DOI 10.37882/2223-2982.2021.12-2.14

\title{
ОСОБЕННОСТИ ПЕРЕВОДА НЕНОРМАТИВНОЙ И СНИЖЕННОЙ ЛЕКСИКИ НА МАТЕРИАЛЕ СОЦИАЛЬНОГО КОМИКСА
}

\section{PECULARITIES OF TRANSLATING FOUL LANGUAGE AND GENERAL PARLANCE (BASED ON THE MATERIAL OF SOCIAL COMIC)}

\section{Yu. Zavyalova}

O. Dobrynina

Summary: The article considers the problems of stylistic stratification of vocabulary and the interaction of its individual lexical levels (stratums), foul language and general parlance in particular, as well as the concept of «foul language» and "parlance». The authors describe the methods of transmitting foul language and general parlance when translating from English into Russian. Comic strips of the Internet resource http://www. respect.com.mx are used as the material for the research. Review of the factual material in the comics under analysis shows that translation of foul language and general parlance employs such techniques as lexical substitution, literal translation, explicatory translation and calquing.

Keywords: English, language vocabulary stratification, general parlance, foul language, obscene vocabulary, translation techniques.
$\Pi$ ри переводе текстов специалисты переводчики часто сталкиваются с проблемой корректного перевода различных лексических единиц, в частности не являющихся стилистически нейтральными. Задача переводчика состоит в том, чтобы, максимально полно воспроизвести смысл, содержание оригинала, его структуру, стиль, а также особенности речи автора, с одной стороны, и чтобы звучало адекватно на переводящем языке, с другой стороны.

В рамках настоящей статьи мы рассматриваем особенности перевода ненормативной и сниженной лексики с английского языка на русский. Материалом исследования послужили социальные комиксы, размещенные на портале http://www.respect.com.mx/ проекта «Респект 2. 0». В рамках исследования были проанализированы 16 комиксов авторов из Великобритании, Германии, Бельгии, Испании, Венгрии и Турции.

Известно, что большую часть состава языка представляет стилистически нейтральная лексика. Природа лексики, не являющаяся стилистически нейтральной, изучалась многими учеными (Арнольд 2002, Гальперин 1999, Девкин 1994, Скребнев 1950, и др.). Так, Р.Н. Попов, Д.П. Валькова и др., кроме стилистически нейтральной, выде-
Завьялова Юлия Анатольевна

к.филол.н., дочент, БУВО Ханты-Мансийского автономного округа - Югры «Сургутский государственный университет» zavyalova_yua@surgu.ru

Добрынина Оксана Владимировна старший преподаватель, БУ ВО образования ХантыМансийского автономного округа - Югры «Сургутский государственный университет» dobrynina_ov@surgu.ru

Аннотация: В статье авторы рассматривают проблемы стилистической стратификации лексики языка и взаимодействия ее отдельных лексических слоев, в частности ненормативной и сниженной лексики, понятие «ненормативная лексика» и «сниженная лексика», описывают приемы передачи ненормативной и сниженной лексики при переводе с английского языка на русский. В качестве материала исследования используются тексты комиксов интернет-ресурса http://www.respect.com.mx. Анализ фактического материала показывает, что при переводе ненормативной и сниженной лексики в анализируемых комиксах используются такие приемы как лексическая замена, дословный перевод, описательный перевод и калькирование.

Ключевые слова: английский язык, стратификация лексики языка, сниженная лексика, ненормативная лексика, обсценная лексика, переводческие трансформации.

ляют книжную и разговорную лексику. В состав книжной лексики входят научная, официально-деловая, газетнопублицистическая и поэтическая; разговорная включает собственно разговорную и просторечную лексику [11, с. 99]. В.Д.Девкин выделяет также книжную, нейтральную и разговорную лексику. По мнению ученого, книжная лексика, которой присущи обобщённость и абстрактность, распространена преимущественно в книжной речи. Нейтральная лексика присутствует во всех функционально-стилистических вариантах литературного языка и служит для обозначения предметов, понятий повседневной жизни, явлений природы и т.п. Она не обладает экспрессивной окраской в отличие от разговорной и книжной лексики. Разговорная лексика характеризуется различной окраской и является неотъемлемой частью лексикона [5, с. 6]. В.Д. Девкин противопоставляет «разговорность» идеально правильному культурному стандарту. По этой причине разговорная лексика может не соответствовать стандарту в разной степени - в минимальной (без нарушения литературности), средне сниженной, (фамильярный слой) и значительной (грубая и вульгарная лексика) [там же, с. 12]. Ю.М. Скребнев относит к лексике высокого стилистического тона архаизмы, книжно-литературные слова, иностранные слова (варваризмы); к лексике сниженного стилистического тона - 
фамильярно-разговорные слова, которые свойственны повседневной, разговорной речи, арготизмы, слэнг и вульгаризмы [14, с. 25]. По мнению И.Р. Гальперина, существуют литературный, нейтральный и разговорный пласты. Первый включает различного рода термины, в том числе архаизмы, историзмы, варваризмы и литературные неологизмы, и распространенные литературные слова. Нейтральный пласт характеризуется стандартным вокабуляром языка, в котором присутствуют нейтральные и распространенные литературные слова, а также распространенные разговорные слова. К разговорному пласту ученый относит распространенные разговорные слова и специальные разговорные слова или нелитературные. Среди нелитературных И.Р. Гальперин выделяет слэнг, жаргонизмы, профессионализмы, диалектизмы, вульгаризмы, разговорные неологизмы [4, с. 67]. Не смотря на созданные классификации ученые отмечают отсутствие жесткого разграничения между группами [4; 14]. В рамках каждой группы также отсутствуют четкие определения, так, например, для понятий «разговорная речь» и «просторечье» ученые предлагают различные дефиниции, поэтому в словарях одно и то же слово может иметь различные пометы - «разг.» или «прост.» [15, с. 375]. В качестве примера можно привести существительное балбес, которое в разных словарях маркируется nрост. (БАС), разг. (МАС), разг.-сниж. (НБТС) [13, с. 10]. Из выше сказанного можно сделать вывод, что ученым не удалось провести четкие границы между лексическими группами, а также внутри каждой группы. Однако можно понять, что ненормативная и сниженная лексика, которая находится в фокусе нашего внимания, включена в группу разговорной лексики / сниженного стилистического тона.

Следует отметить, что однозначного понимания понятий «сниженная лексика» и «ненормативная лексика» также не существует. Некоторые ученые проводят параллель между вышеназванными понятиями. Согласно толковому словарю С.И. Ожегова, сниженная лексика отличается от литературного языка или языкового стандарта, где языковой стандарт рассматривается как образцовый, нормализованный язык [10, с. 5]. Другими словами, сниженная лексика находится за пределами литературного языка, вне норм языкового стандарта, то есть является ненормативной. Т.М. Беляева и В.А. Хомяков выделяют нестандартную лексику, к которой относятся специальные сленгизмы (жаргонизмы, кентизмы), общие сленгизмы, «низкие» коллоквиализмы и вульгаризмы [2, с. 16]. И.А. Стернин рассматривает нормативность / ненормативность лексики как категорию допустимости / недопустимости ее публичного употребления и относит к ненормативной лексике сниженную, бранную и нецензурную. В рамках сниженной лексики он выделяет сленг, жаргон, просторечие, вульгарную лексику. Употребление сниженной лексики чаще всего не отражает намерения говорящего как-либо оскорбить или унизить адресата, оно мотивировано эмоциональным состоянием говорящего и отражает уровень его культуры, воспитанности. Бранная или инвективная содержит неодобрительную оценку объекта номинации. Употребление данной лексики отражает как намерение оскорбить или унизить адресата, так и спонтанный выброс эмоций. Нецензурная лексика выражает сильные эмоции говорящего, как отрицательные, так и положительные; может содержать намерение оскорбить, а также не иметь такой установки и использоваться для выплеска эмоций говорящего [16]. В.А. Хомяков называет ненормативную лексику обсценной, которая рассматривается как сегмент бранной лексики, включающий грубые бранные выражения, также ученый считает, что обсценная лексика отражает спонтанную речевую реакцию, очень часто на неожиданную негативную ситуацию [17, с. 105]. B.М. Мокиенко понимает обсценную и бранную лексику взаимно пересекающимися, хотя не полностью неидентичными [8, с. 60]. Н.Г. Московцев и С.М. Шевченко разделяют обсценную лексику на эвфемизмы, сленг, ругательства $[9$, c. 112].

Таким образом, сниженная и ненормативная лексика является эмоциональной и экспрессивной. Для переводчика степень соотносимости экспрессии иноязычной и родной лексики представляет собой довольно сложный вопрос. Часто переводчики с учетом несовпадения степени экспрессии дают перевод менее экспрессивными эквивалентами родного языка. Однако при переводе кроме стиля автора и системы его образов нужно учитывать семантику лексической единицы, степень сниженности и степень экспрессии в языке оригинала. По мнению Л.К. Латышева, перевод должен рассматриваться как тоже самое, но только на другом языке, как копия исходного текста (на другом языке). Если сравнивать с общением, то общение с помощью перевода должно быть таким же, как и обычное, одноязычное общение, только с участием промежуточного звена, в частности переводчика. С другой стороны, общение при помощи переводчика продолжает оставаться двуязычным, то есть человек продолжает видеть в другом иностранца и не хочет, чтобы происходила подмена, например, чтобы вместо Джона выступал Иван [7, с. 15]. Качественным переводом называет К.И. Чуковский тот перевод, где переводчик наиболее точно передал ту степень воздействия на читателя, которую испытывает носитель языка при чтении оригинального текста. При этом необходимо обращать внимание на то, чтобы текст перевода не содержал элементов с резкой национально-культурной окраской [18, с. 116]. Из сказанного выше следует, что одноязычное общение с переводом представляет собой лишь идеал, к которому нужно пытаться приблизиться, но который является недостижимым. Степень приближения зависит от мастерства переводчика, свойств переводимого текста и способа выполнения перевода [7, с. 17]. Очень важен правильный выбор типов и приемов перевода. 
В.Н. Комиссаров, говоря о типах перевода, использует такие термины как «адекватный перевод», «эквивалентный перевод», «точный перевод», «буквальный перевод» и «свободный (вольный) перевод» [6, с. 21]. В этой связи необходимо упомянуть, что процесс перевода включает в себя два базовых этапа, согласно которым переводчик трансформирует текст оригинала в текст перевода: полноценное декодирование переводчиком содержание оригинала и адекватный выбор варианта перевода. По мнению С.И. Влахова и С.П. Флорина, феномен «непереводимого в переводе» все же существует, и переводчики нередко сталкиваются с ним на практике [3].

Чтобы максимально приблизиться к оригиналу текста переводчики часто используют при переводе ненормативной и сниженной лексики переводческие трансформации. Как известно, существуют различные классификации переводческих трансформаций. Я.И.Рецкер выявляет лексические и грамматические трансформации [12, с. 72]; Л.С. Бархударов - перестановки, замены, добавления, опущения [1, с. 230]. Анализ перевода проводился на основе классификации В. Н. Комиссарова, поэтому следует подробнее остановиться на данной классификации. В.Н. Комиссаров выделяет лексические, грамматические и смешанные трансформации. К лексическим трансформациям ученый относит транскрипцию, транслитерацию, калькирование, лексико-семантические замены, которые включают в себя конкретизацию, генерализацию и смысловое развитие. Среди грамматических трансформаций В.Н. Комиссаров выделяет грамматические замены, синтаксическое уподобление (дословный перевод), членение и объединение предложений. В составе смешанных переводческих трансформаций находятся экспликация (описательный перевод), антонимический перевод, и компенсация [6, c. 172].

На основе выше представленной классификации были проанализированы тексты социальных комиксов английского и русского языков, выявлены и сопоставлены лексические единицы сниженной и ненормативной лексики в текстах комиксов обоих языков и описаны приемы перевода лексики с английского языка на русский. Ниже представлен анализ некоторых комиксов.

В комиксе You're the baddie! читателю предлагается следующий диалог:

Die, stupid little Frenchy! - No way, Flemish pig!

Умри, дурацкий недофранцуз! - Фиг тебе, фламашка вонючий! [19]

В данном отрывке мы наблюдаем присутствие оскорбительной лексики, которая используется для презрительного обозначения национальностей. Переводчик в первом случае использует прием смыслового развития и преобразует словосочетание little Frenchy в недофранцуз.
Несмотря на то, что слово little должно смягчать отрицательную оценку, здесь оно производит обратный эффект. Приставка недо- обладает лучшей сочетаемостью со словом француз, хотя оно используется вместо общепринятого словарного соответствия лягушатник. В переводе словосочетания Flemish pig переводчик пользуется заменой частей речи и прилагательное+существительное переводит русской конструкцией существительное + прилагательное.

I'll get you, you ugly French-speaker! - Me? You mean just 'cause I think you're wrong I should shut up and do as I'm.

Ладно, сейчас не до тебя, лягушатник недоделанный, ты у меня еще получишь! - За что, интересно знать? За то, что у меня есть свое мнение? Или ты хочешь, чтобы я всю жизнь молчал в тряпочку? [там же]

В русском варианте перевода данной конструкции происходит усиление эмфатизации засчет инверсии и контекстуального подбора причастия, заменившего прилагательное ugly, в словосочетании лягушатник недоделанный. Именно оно придает отрицательную коннотацию всему словосочетанию, так как само по себе существительное French-speaker является нейтральным. Использование же просторечного выражения молчать в тряпочку вместо заткнуться (shut up) смягчает общий тон речи персонажа.

You just shut your big mouth, you bad Walloon!

Ах ты, мерзкий валлон! [там же]

Здесь же выражение shut your big mouth передается нулевым переводом, а словосочетанию bad Walloon переводчик при помощи лексическо-семантической замены находит более эмоционально окрашенное прилагательное вместо нейтрального.

Oh shit! Look at that "Monsieur Perfect" - your friends have brought out those old planes we gave you!

Блин! Видал, че делается, месье «Респект»? твои дружки выкатили старые самолеты, которые мы же вам и оставили! [там же]

При передаче значения слова shit на русский язык переводчик использует более мягкую по значению лексическую, следовательно, перевод в данном примере можно считать эвфемистическим.

Stupid pigs! Why are they bombing us?

Поганые лягушатники! Зачем бомбить эту зону? [там же]

В переводе данного выражения переводчик применяет контекстуальную лексическую замену в отношении обоих компонентов словосочетания, при этом не усиливая отрицательную коннотацию русского.

He calls her a dirty Walloon.

Он назвал ее вонючей валлонкой [там же].

Находя лексико-семантическую замену слову dirty 
автор перевода усиливает отрицательную коннотацию словосочетания на русском языке.

В комиксе Categoria мы находим такие примеры сниженной лексики, как loser, cool, cools, jocks, nerds, beauties, freaks, swot. Многие из этих слов переданы переводчиком на русский язык словарными соответствиями: loser - лузер, cool-круто / клевый, cools - крутые, freak(s) - фрики / урод, swot-ботанка. Такой перевод полностью сохраняет замысел и стиль речи автора и является адекватным. Что касается слова beauties, переводчик передает его с помощью генерализации гламурные девочки, и тем самым усиливает коннотативную оценку в русском языке. Усиление происходит и в перводе слова jocks - бугаu. В толковом словаре дается следующее более нейтральное определение: спортсмен (особенно в колледже). В случае же перевода слова nerds -очкарики продуктивным приемом перевода становится конкретизация, что тоже усиливает коннотацию.

Переводчик передает нулевым переводом слово weirdo (чмо / придурок / урод) в следующих предложениях, тем самым смягчая отрицательную оценку:

Just adding a bit of colour to your fancy headgear, weirdo!

Финальный штрих к твоей дебильной шапочке! [там же]

Интересно заметить, что в данном примере негативную окраску приобретает фраза, лишенная этого в оригинале: fancy headgear переведено выражением дебильная шапочка, что сохраняет определенное неодобрение во всей конструкции.

Crap! I can't think of anything!

Черт, не могу ничего придумать! [там же]

В вышеприведенном примере при переводе смягчается интенсивность отрицательной коннотации. Переводчик в данном контексте выбирает прием лексической замены в рамках инфернальной лексики. Интересно, что в США слово crap (дерьмо / лажа) считается более грубым, чем в Великобритании.

Chaos - Бардак; More chaos! - Большой бардак; Even more chaos! - Ужасный бардак [там же].

Интересен пример перевода слова chaos при помощи лексической замены - в русском тексте применяется прием дисфемизации, изначально нейтральное понятие приобретает грубое или непристойное обозначение, каковым и обладает слово бардак. Наблюдается значительное снижение разговорной нормы.

Некоторые сленговые выражения обнаруживаются в комиксе Eve, но переводчик чаще всего прибегает к нулевому переводу слов на русский или использует лексические замены, тем самым зачастую нейтрализуя оценку в русском языке. В следующих примерах английское chicks, в словарном переводе означающее физически привлекательная молодая женщина, передано словом иностранка, а прилагательное skanky, образованное от существительного skank (физически не привлекательная женщина) в принципе сохраняет коннотацию.

She's foreign though. All foreign chicks have hairy arms! [там же]

Так она ж, это, иностранка. У них у всех руки волоcamble.

You might get some skanky gorilla germs if you stand too close!

Не стой к ней близко, а то подхватишь себе ее ужасных горильих микробов [там же].

В одном из примеров переводчик применяет эвфемизацию, что, хотя и подменяет смысл, но звучит достаточно экспрессивно. Для слова hot мы находим следующее определение в словаре: сексуально привлекательная женщина. В русском переводе применена генерализация, но коннотативная оценка сохраняется. Английское слово man тоже относится к жаргонизмам и на русский язык передано словарным соответствием мужик без потери оценки.

G-go for her, man, she is hot.

Добивайся ее, мужик, она супер! [там же]

В тексте комикса Fascist Chicken обнаружен случай употребления вульгаризма scum, которому переводчик находит лексическую замену нечисть, и которая смягчает крайне негативную коннотацию английского слова. Жаргонизм роор встречается в тексте три раза и дважды переводится русским словом дерьмо и один раз переводчик использует слово какашки. Мы считаем, что наиболее адекватный и репрезентативный перевод представляет последний вариант, так как в словаре английское слово имеет помету baby talk, а первый вариант перевода чрезмерно завышает негативную оценку. И хотя в комиксе речь идет о курице, которая выживала всех животных со скотного двора весьма жестокими методами (скрытый смысл заключен и в названии комикса), все же сюжет преподносится в юмористической манере и грубый перевод здесь неуместен. В тексте встречается и производная роopeater, которая передана описательным переводом mе, кто ест свои какашки и прекрасно сохраняет и смысл, и коннотацию оригинальной единицы.

В комиксе Why Always the Smaller One? представлены некоторые единицы обсценной лексики с крайне негативной коннотацией. Например, вульгаризм cocksucker и сленговое fag, которые переводчик передает лексическими заменами лох и ушлепок соответственно, тем самым смягчая эмоциональную оценку. Такой перевод оправдан, так в русском языке снижение литературной нормы в отношении проникновения обсценной лексики в речь происходит медленнее и употребление ее в литературных произведениях все же 
считается неприемлемым. Сленговое слово сорs передано транслитерацией + калькированием копы с coxpaнением формы множественного числа.

Таким образом, рассмотренные ненормативные лексические единицы в текстах социальных комиксов переводятся на русский язык с помощью лексической замены, дословного перевода, описательного перевода и калькирования. Самым распространенным приемом является лексическая замена. Следует также отметить, что в текстах комиксов для лексических единиц характерен адекватный перевод. Для уменьшения степени экспрес- сии исходных слов и выражений переводчик иногда использует эвфемистический перевод.

Суммируя вышесказанное, необходимо сказать, что создание адекватного перевода является важной задачей переводчика. Структура, содержание и потенциал воздействия текстов оригиналов и переводов должны быть сопоставимы. Достичь такого результата при переводе сниженной и ненормативной лексики достаточно сложно. Для этого переводчик должен обладать знаниями, опытом, а также переводческой интуицией.

\section{ЛИТЕРАТУРА}

1. Бархударов Л.С. Язык и перевод / Л.С. Бархударов. - М.: Международные отношения, 1975. - 237 с.

2. Беляева Т.В., Хомяков В.А. Нестандартная лексика английского языка / Т.В. Беляева, В.А. Хомяков. - 2-е. изд., - М.: «ЛИБРОКОМ», 2010. - 136 с.

3. Влахов С.И., Флорин С.П. Непереводимое в переводе / С.И. Влахов, С.П. Флорин. - 4-е изд.- М.: «Р.Валент», 2009. - 360 с.

4. Гальперин И.Р. Лексикология английского языка / И.Р. Гальперин. - М.: Высшая школа, 1999. - 296 с.

5. Девкин В.Д. Немецко-русский словарь разговорной лексики / В.Д. Девкин. - М., Русский язык, 1994. - 768 с.

6. Комиссаров В.Н. Теория перевода (лингвистические аспекты) / В.Н. Комиссаров. - М.: Высш. шк., 1990. - 253 с.

7. Латышев Л.К. Технология перевода / Л.К. Латышев. - М.: НВИ-ТЕЗАУРУС, 2001. - 280 с.

8. Мокиенко В.М. Русская бранная лексика: цензурное и нецензурное / В.М. Мокиенко // Русистика. - Берлин, 1994. - №1/2. С. 50-73.

9. Московцев Н., Шевченко С. Вашу мать, сэр! Иллюстрированный словарь американского сленга без купюр / Н. Московцев, С. Шевченко. - 3-е изд., СПб.: Питер. - 2012. - 384 с.

10. Ожегов С.И. Очередные вопросы культуры речи / С.И. Ожегов //Вопросы культуры речи. Вып.1. - М., 1955.- 239 с.

11. Попов Р.Н., Валькова Д.П., Маловицкий А.К., Федоров А.К. Современный русский язык / Р.Н. Попов, Д.П. Валькова, Л.Я. Маловицкий, А.К. Федоров. М., Просвещение, 1978. - 170 с.

12. Рецкер Я.И. Что же такое лексические трансформации? «Тетради переводчика» / Я.И. Рецкер. - М.: Международные отношения, 1980. - №17. С.72-84.

13. Свиридова Е.А. Взаимодействие книжной и разговорно-просторечной лексики в современной прессе: автореферат дис. .... кандидата филологических наук : 10.02.01 / Свиридова Екатерина Александровна; [Место защиты: Тамб. гос. ун-т им. Г.Р. Державина]. - Мичуринск, 2013. - 26 с.

14. Скребнев Ю.М. Стилистика английского языка / Ю.М Скребнев. - Л., 1950. - 240 с.

15. Соломина Е.В. Разграничение литературного языка и городского просторечия в обыденном сознании носителей русского литературного языка. Интерпретация текста: лингвистический, литературоведческий и методический аспекты: материалы международной научн. конф. (Чита, ЗабГГПу, 30-31 октября 2009 г.) // Забайкальский гос. гум.-пед. ун-т. Чита, 2009.

16. Стернин И.А. Неприличная форма высказывания в лингвокриминалистическом анализе текста // Юрислингвистика. 2011. №11. URL: https://cyberleninka. ru/article/n/neprilichnaya-forma-vyskazyvaniya-v-lingvokriminalisticheskom-analize-teksta-1 (дата обращения: 06.11.2021).

17. Хомяков В.А. Некоторые типологические особенности нестандартной лексики английского и русского языков / В.А. Хомяков // Вопросы языкознания. №3. - М., $1992-144$ C.

18. Чуковский К.И. Высокое искусство / К.И. Чуковский. - М.: Советский писатель, 1988. - 384 с.

19. Respect [Электронный ресурс]. - Режим доступа: http://www.respect.com.mx/de/ (дата обращения: 20.02.2021). 